\title{
Physico-chemical characterization of polyamide NF / RO membranes: insight from streaming current measurements
}

\author{
E. Idil Mouhoumed ${ }^{1}$, A. Szymczyk ${ }^{1, *}$, A. Schäfer ${ }^{2,3}$, L. Paugam ${ }^{1}$, Y.H. La ${ }^{4}$ \\ ${ }^{1}$ Université de Rennes 1, Institut des Sciences Chimiques de Rennes (UMR CNRS 6226), 263 \\ Avenue du Général Leclerc, 35042 Rennes, France \\ ${ }^{2}$ Water and Environmental Science and Engineering, Nelson Mandela African Institute of \\ Science and Technology, Arusha, Tanzania \\ ${ }^{3}$ Institute of Functional Interfaces, Karlsruhe Institute of Technology, Hermann-von- \\ Helmholtz-Platz 1, 76344 Eggenstein-Leopoldshafen, Germany \\ ${ }^{4}$ IBM Almaden Research Center, 650 Harry Road, San Jose, CA 95120, USA
}

*Corresponding author: anthony.szymczyk@univ-rennes1.fr

\begin{abstract}
Tangential streaming current measurements were performed to investigate the surface charge properties and the charge formation mechanism of various NF /RO membranes. Unlike what is usually done in electrokinetic studies of membranes, experiments were conducted with degassed background solutions under a controlled atmosphere by means of nitrogen gas in order to get accurate electrokinetic measurements even in the basic range of $\mathrm{pH}$. It was demonstrated that the streaming current technique implemented with these rigorous experimental conditions is a reliable tool to verify the presence of an additional coating on a commercial TFC membrane. It was also shown these electrokinetic measurements allow a more clear discrimination between coated and uncoated membranes than the ATR-FTIR technique. Moreover, experiments performed with and without a nitrogen environment revealed specific adsorption of bicarbonate and carbonate ions coming from the dissolution of carbon dioxide in the air onto the surface of RO polyamide membranes containing hexafluoroalcohol functional groups.
\end{abstract}




\section{Introduction}

The increasing world population and the growing demand for fresh water bring to light limitations concerning fresh water reserves in the world. The United Nations predicts that by 2015, five billion people (about two-thirds of the world population) will live in water-stressed regions with severe issues related to water shortage for human consumption, industry and agriculture $[1,2]$. The only viable methods to increase water supply beyond what is available from the hydrological cycle are desalination and water reuse [3]. Membrane technology is one of the most widely adopted technologies in these areas [4]. Nanofiltration (NF) and reverse osmosis (RO) are particularly well-suited for desalination and water reclamation. RO is the leading desalination process used worldwide [5] and NF is considered as a separation process with one of the highestexpected growths in the coming years.

Most current NF/RO membranes are thin film composite (TFC) made with three distinct layers, namely a polyester non-woven support layer, a polysulfone intermediate layer and a thin polyamide skin layer. Unfortunately, the processes and exact chemistries for producing commercial NF/RO membranes are proprietary, which greatly limits membrane users' understanding of the physical and chemical properties of these membranes [6]. Moreover, the surfaces of some membranes are often modified by post-treatment steps, such as the application of a neutral hydrophilic coating layer in order to improve membrane performances in terms of permeability, rejection, or fouling [1,4, 6-9].

Characterization of the physico-chemical properties of $\mathrm{NF} / \mathrm{RO}$ membranes is crucial for understanding their separation performance. Membrane morphology can be studied by microscopy techniques such as scanning electron microscopy (SEM) [2], atomic force microscopy (AFM) [2] or transmission electron microscopy (TEM) [6]. Characterization techniques such as X-ray photoelectron spectroscopy (XPS) provide insight into the elemental composition (except for hydrogen) of the top surface of a membrane (the penetration depth of the signal is only a few nanometers) $[1,2,4,6,7]$ while attenuated total reflection Fourier transform infrared spectroscopy (ATR-FTIR) provides information about the functional groups present from the top surface to a depth ranging from $\sim 100 \mathrm{~nm}$ to a few microns $[4,6$ 8]. Determining the zeta potential of membranes is also of great interest since it enables the characterization of the membrane material in contact with a liquid phase. For instance, membrane zeta potential has been used to correlate the transport of both inorganic and organic solutes through RO and NF membranes $[10,11]$. In addition, flux performance and fouling 
behavior of a membrane are also affected by its zeta potential $[6,12]$. Zeta potential and electrokinetic charge density of membranes can be inferred from electrokinetic methods such as streaming potential and streaming current. Since these techniques permit to consider the compensation of the surface charge by the ions of the electrical double layer on the liquid side of the interface, they are particularly useful when investigating problems of practical relevance. However, the interpretation of experimental data is not unambiguous depending on both the nature and the structure of the membrane under consideration [13-18] and the interpretation of electrokinetic data require a thorough analysis.

In this work, we employ the streaming current technique in tangential mode to investigate the electrokinetic properties of different $\mathrm{NF} / \mathrm{RO}$ polyamide membranes. It is shown that streaming current measurements performed with an appropriate experimental protocol can reveal unambiguously the presence of a coating layer onto the membrane surface. Specific adsorption of bicarbonate and carbonate ions on the surface of thin-film composite polyamide membranes containing hexafluoroalcohol groups is also verified by electrokinetic measurements performed with and without the presence of carbon dioxide.

\section{Theoretical background}

The streaming current technique in tangential mode consists of applying a hydrostatic pressure gradient across a channel formed by two identical charged surfaces facing each other and filled with an electrolyte solution. The application of a pressure gradient forces the electrolyte solution to move tangentially to the charged surfaces, pulling the excess mobile ions within the electrical double layers and creating a streaming current.

The streaming current through the channel $\left(I_{s}\right)$ is obtained by the integration of the local streaming current density (given by the product of local fluid velocity and local volume charge density) over the channel cross section, i.e. for a parallelepipedic channel:

$$
I_{s}=-2 W \int_{0}^{h_{c h} / 2} v(x) \rho(x) d x
$$

where $W$ and $h_{c h}$ are the channel width and height, respectively, $v(\mathrm{x})$ is the local velocity of the fluid, $\rho(\mathrm{x})$ the local volume charge density, and $\mathrm{x}$ represents the coordinate normal to the 
solid $\operatorname{surface}\left(x=h_{c h} / 2\right.$ at the wall). Note that the sign "minus" in Eq. (1) was set conventially so that the streaming current and the zeta potential have the same sign (see Eq. (2) below).

In laminar flow and for a sufficiently wide channel width respect to the Debye length of the channel-filling solution, Eq. (1) takes the form:

$$
I_{s}=\frac{W h_{c h} \varepsilon_{0} \varepsilon_{r} \Delta P}{\eta L} \zeta
$$

where $\mathrm{L}$ is the channel length, $\varepsilon_{0}$ is the vacuum permittivity, $\varepsilon_{\mathrm{r}}$ and $\eta$ are the dielectric constant and the dynamic viscosity of the electrolyte solution, respectively. $\Delta P$ is the pressure difference between the channel ends and $\zeta$ is the zeta potential which is defined as the electrostatic potential in the hydrodynamic plane of shear [19].

Although Eq. (2) can be used with confidence for dense materials [20,21] it may break down when electrokinetic measurements are performed with ion-permeable materials such as macroporous membranes [15] or composite membranes with coarse-porous support layers [16].

Indeed, Yaroshchuk and Luxbacher have recently demonstrated that, because the whole thickness of the membranes is exposed to the hydrodynamic flow in most experimental cells, a non negligible part of the streaming current is likely to flow though the porous sublayer(s) [15]. In other words the system behaves as an electrical circuit in parallel as illustrated in Fig. 1 and the experimental streaming current $\left(I_{s}^{\text {tot }}\right)$ can be expressed as the sum of the current flowing through the channel $\left(I_{s}^{c h}\right)$ and the current flowing through the porous sublayer(s) of each membrane $\left(I_{s}^{m b}\right)$ :

$$
I_{s}^{\text {tot }}=I_{s}^{c h}+2 I_{s}^{m b}=\left(\frac{W h_{c h} \varepsilon_{0} \varepsilon_{r} \Delta P}{\eta L} \zeta_{s u r f}+\frac{2 W h_{m b}^{e f f} \varepsilon_{0} \varepsilon_{r} \Delta P}{\eta L} \zeta_{m b}\right)
$$

where $\zeta_{\text {surf }}$ and $\zeta_{m b}$ are the zeta potentials of the membrane surface and the porous body of membranes, respectively, and $h_{m b}^{\text {eff }}$ is a lump parameter defined as the effective height in which 
the streaming current flows through a single membrane body $\left(h_{m b}^{e f f}\right.$ includes the membrane thickness as well as the porosity and the pore tortuosity).

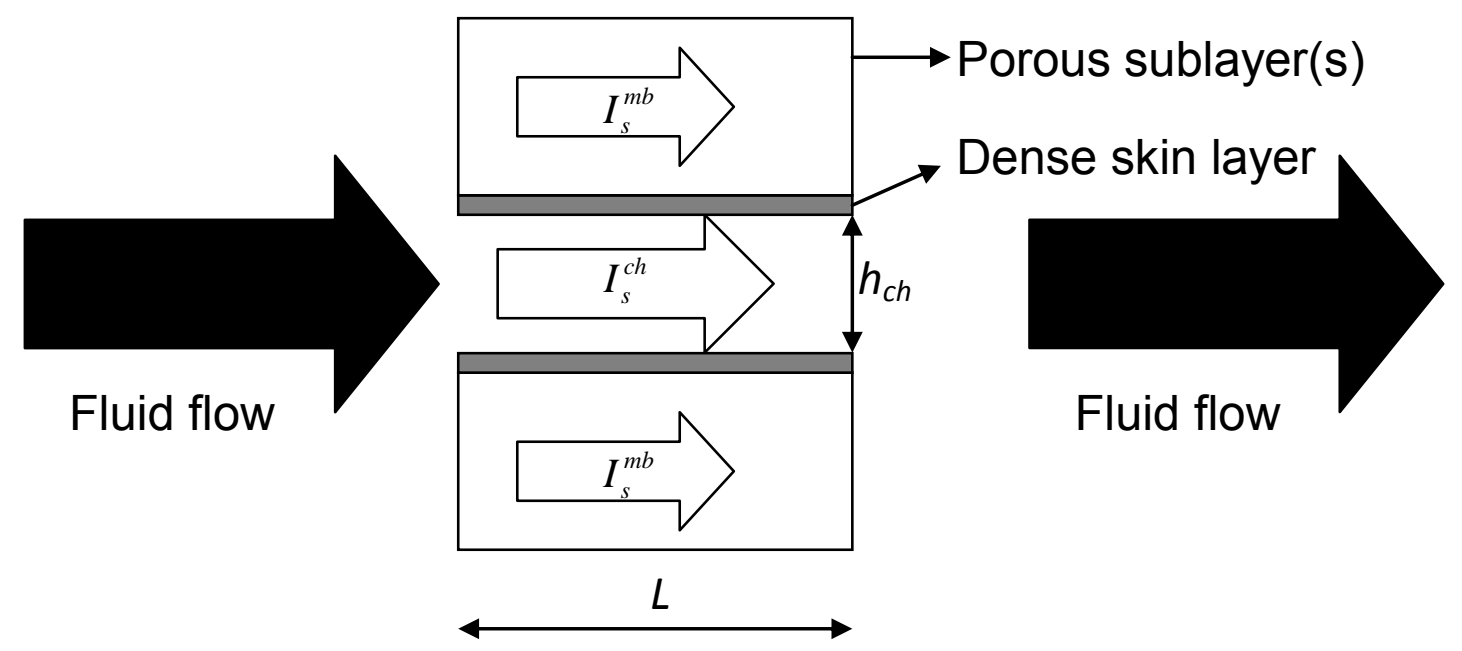

Fig.1: Distribution of the streaming current during tangential electrokinetic experiments with membranes whose porous structures are exposed to the hydrodynamic fluid flow. $I_{s}^{c h}$ is the streaming current flowing through the channel, $I_{s}^{m b}$ the streaming current flowing through the porous sublayer(s) of the membrane samples, $L$ is the sample length, and $h_{c h}$ is the channel height.

\section{Experimental}

\subsection{Membranes}

A total of $9 \mathrm{RO}$ and NF membranes were characterized: 2 seawater RO membranes (SW30HR and i-phobe 2), 3 brackish water RO membranes (BW30LE, BW30 and ESPA4) and 4 NF membranes (NF270, NF90, TFC-SR2 and TFC-SR3). BW30LE, BW30, SW30HR, NF270 and NF90 were purchased from Dow FilmTec, TFC-SR2 and TFC-SR3 were provided by Koch Membrane Systems, ESPA4 from Hydranautics and i-phobe 2 was provided by IBM Almaden Research Center (USA).

All membranes are thin film composite (TFC) membranes with an active layer in polyamide on a polysulfone intermediate layer and a polyester support layer. 
[a]

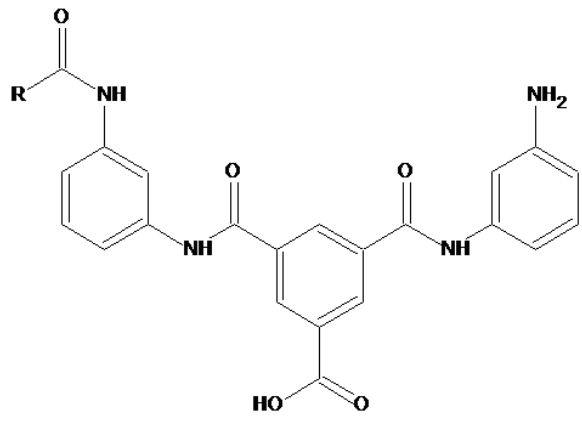

Full aromatic polyamide

(SW30HR, BW30LE, BW30, ESPA4, NF90)<smiles>[R]C(=O)N1CCN(C(=O)c2cc(C(=O)O)cc(C(=O)N3CCNCC3)c2)CC1</smiles>

Semi aromatic polyamide

(NF270, TFC-SR2, TFC-SR3)

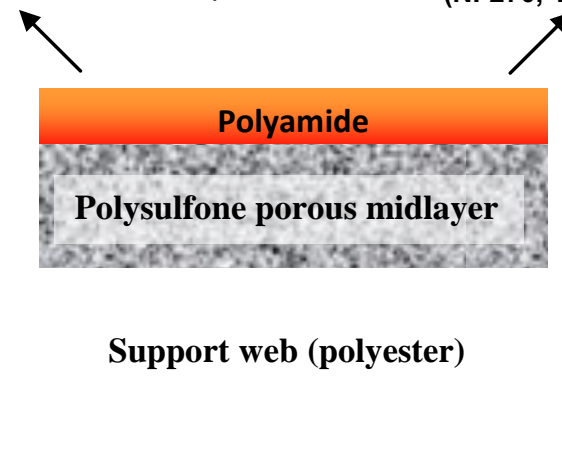

Conventional polyamide membranes

[b]

HFA-polyamide top layer

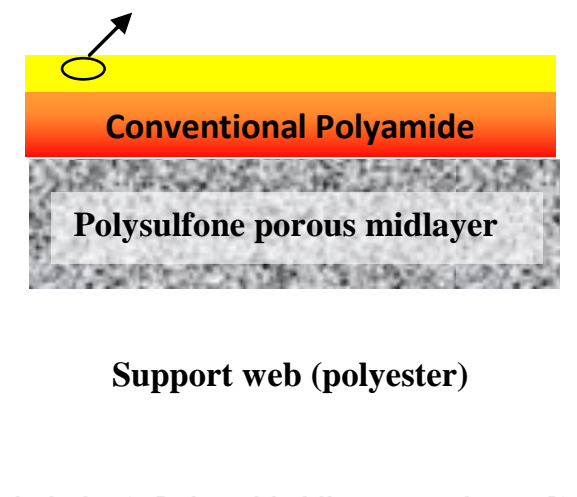

i-phobe 2: Polyamide bilayer membrane [22]

Fig.2: Chemical structures of polyamide TFC membranes; [a]: commercial TFC membranes; [b]: bilayer i-phobe 2 membrane. 
The active layers of NF270, TFC-SR2 and TFC-SR3 membranes are made of semi-aromatic polyamide obtained by interfacial polymerization between trimesoyl chloride (TMC) and piperazine. The active layers of BW30, BW30LE, ESPA4, SW30HR and NF90 membranes are made of a full aromatic polyamide obtained by interfacial polymerization between TMC and $m$-phenylenediamine (MPD) $[4,6,7]$.

The i-phobe 2 membrane is a novel TFC membrane featuring a polyamide bilayer prepared on a porous polysulfone support using sequential interfacial polymerization (a polyamide membrane prepared by interfacial polymerization between trimesoyl chloride and $\mathrm{m}$ phenylenediamine monomers is subsequently immersed into an alkaline aqueous solution of 3, 3'-bis(1-hydroxy-1-trifluoromethyl-2,2,2-trifluoroethyl)-4,4'-methylenedianiline (HFAMDA) to form a hexafluoroalcohol (HFA)-substituted aromatic polyamide layer on the surface of a conventional aromatic polyamide layer [22]).

The chemical structures of the various polyamide TFC membranes used in this study are shown in Fig.2.

Prior to characterization, the membrane samples used for both ATR-FTIR and streaming current experiments were immersed in a water-ethanol mixture and sonicated for $5 \mathrm{~min}$ in order to remove conservatives. The samples were further rinsed twice with deionized water (resistivity: $18 \mathrm{M} \Omega \mathrm{cm}$ ) and sonicated $(2 \times 2 \mathrm{~min})$.

\subsection{Solutions}

An electrolyte solution $\left(10^{-3} \mathrm{~mol} \mathrm{~L}^{-1}\right)$ used in electrokinetic measurements was prepared from $\mathrm{KCl}$ (Fischer Scientific) and deionized water (resistivity: $18 \mathrm{M} \Omega \mathrm{cm}$ ). The $\mathrm{pH}$ was adjusted with $0.1 \mathrm{~mol} \mathrm{~L}^{-1} \mathrm{HCl}$ and $\mathrm{KOH}$ solutions (Fisher Scientific). Ethanol (>99\%; Fischer Scientific) was used to prepare water/alcohol mixtures used to remove membrane conservatives.

\subsection{Streaming current measurements}

Streaming current measurements were performed with a SurPASS electrokinetic analyzer (Anton Paar GmbH, Austria). All measurements were conducted with an adjustable-gap cell which makes possible to vary the distance between the two membrane samples with micrometric screws without dismounting the cell (a detailed description of the cell is available in the manufacturer's manual [23]). 
The membrane was cut and adjusted to the dimensions of the sample holders (i.e. $L=2 \mathrm{~cm}$ and $W=1 \mathrm{~cm}$ ) and fixed using double-sided adhesive tape. To prevent any leakage between the membranes and the sample holders, membranes were firmly pressed against sample holders for 30-60 s, paying special attention to the edges exposed to the hydrodynamic flow. The solution flow was created by a pair of syringe pumps and streaming current was measured with a pair of reversible $\mathrm{Ag} / \mathrm{AgCl}$ electrodes (surface area: $10 \mathrm{~cm}^{2}$ ).

The streaming current was measured and recorded for increasing pressure differences up to 300 mbar, the flow direction being changed periodically. Using electrodes with a large surface area and alternating the direction of solution flow limits the electrode polarization during measurements.

A preliminary study based on a series of streaming current measurements performed at various channel heights $\left(h_{c h}\right)$ led to the conclusion that the contribution of porous sublayers to the experimental streaming current could be reasonably neglected for all membranes tested in the present work (results not shown; see references 15 and 16 for methodological details). The result is most likely attributed to dense skin layers (polyamides) and a hydrophobic nature of porous sublayers (polysulfone), which hinder permeation of a solution through the porous sublayers during tangential electrokinetic measurements. Based on this preliminary result experimental data shown hereafter were obtained by performing electrokinetic measurements with a single channel height $\left(h_{c h}\right)$ of $95 \pm 5 \mu \mathrm{m}$ to ensure laminar and fully developed flows (it has been recently demonstrated that electrokinetic measurements performed under undeveloped flow conditions can lead to misinterpretation of streaming current experimental data [18]).

Since the contribution of the membrane sublayers to the streaming current is ignorable, zeta potential was calculated by using Eq. (2).

All experiments were performed with $10^{-3} \mathrm{~mol} \mathrm{~L}^{-1} \mathrm{KCl}$ solution at room temperature, i.e. (20 $\pm 2{ }^{\circ} \mathrm{C}$ ) and under controlled atmosphere (unless indicated) by bubbling $\mathrm{N}_{2}$ gas into the beaker containing the electrolyte solution (and maintaining a nitrogen headspace) that is further pumped through the measuring cell.

\subsection{ATR-FTIR spectroscopy}

Streaming current measurements were complemented by ATR-FTIR spectroscopy performed with a Spectrum 100 Fourier transform infrared spectrometer (Perkin Elmer) equipped with a diamond crystal ATR element. Each spectrum was averaged from 40 scans collected from 
650 to $4000 \mathrm{~cm}^{-1}$ at $2 \mathrm{~cm}^{-1}$ resolution. Membrane samples were dried for two days under vacuum before performing ATR-FTIR spectroscopy experiments.

\section{Results and discussion}

ATR-FTIR spectra of NF90, BW30, BW30LE and SW30HR membranes are shown in Fig. 3a for wave numbers ranging from $650-4000 \mathrm{~cm}^{-1}$. The four spectra are similar for wave numbers between 650 and $\sim 1800 \mathrm{~cm}^{-1}$. Due to the relatively deep penetration depth of the signal both the polysulfone sublayer and the polyamide skin layer were probed. The bands at 1541,1609 and $1641 \mathrm{~cm}^{-1}$ are assignable to the fully aromatic polyamide skin layers of the four different membranes while bands at 1145, 1180, 1235, 1280, 1350, 1385, 1488 and 1587 $\mathrm{cm}^{-1}$ are attributed to the polysulfone intermediate layers [7].

As mentioned above, the spectra are identical for wave numbers lower than $1800 \mathrm{~cm}^{-1}$, which confirms that the same chemical functions are present in the four membranes. Slight differences among thesefour membranes appear, however, for wave numbers higher than $2600 \mathrm{~cm}^{-1}$ as shown in Fig. 3b. For both NF90 and BW30LE membranes, the overlap of the $\mathrm{N}-\mathrm{H}$ stretching band of amide groups and that of the $\mathrm{O}-\mathrm{H}$ stretching band of carboxylic acid functions resulting from the incomplete cross-linking of the polyamide skin layer leads to an additional shoulder peak at $3470 \mathrm{~cm}^{-1}$ (N-H stretching) near the wide band centered at 3300 $\mathrm{cm}^{-1}$ (O-H stretching). On the other hand, the shoulder peak corresponding to N-H stretching vibration is absent in the spectra of both BW30 and SW30HR membranes. The absence of the shoulder peak at $3470 \mathrm{~cm}^{-1}$ was attributed by Tang et al. [6] to the presence of a coating layer rich in alcohol functions such as polyvinyl alcohol (PVA) resulting from a membrane posttreatment step. Results shown in Fig. 3b therefore suggest that both BW30 and SW30HR membranes are coated whereas BW30LE and NF90 membranes are not. Tang et al. also pointed out that the additional surface coating materials results in stronger stretching vibrations of aliphatic $\mathrm{C}-\mathrm{H}$ between 2900 and $3000 \mathrm{~cm}^{-1}$. However, in our study, there was no significant difference among the four membranes in the range of $2900 \sim 3000 \mathrm{~cm}^{-1}$. The shape of the broad band centered at $3300 \mathrm{~cm}^{-1}$ therefore appears as a more reliable indicator of the presence of a coating layer on a TFC membrane (note that a similar conclusion can be drawn from results reported by Widjaya et al. [4]). 
[a]
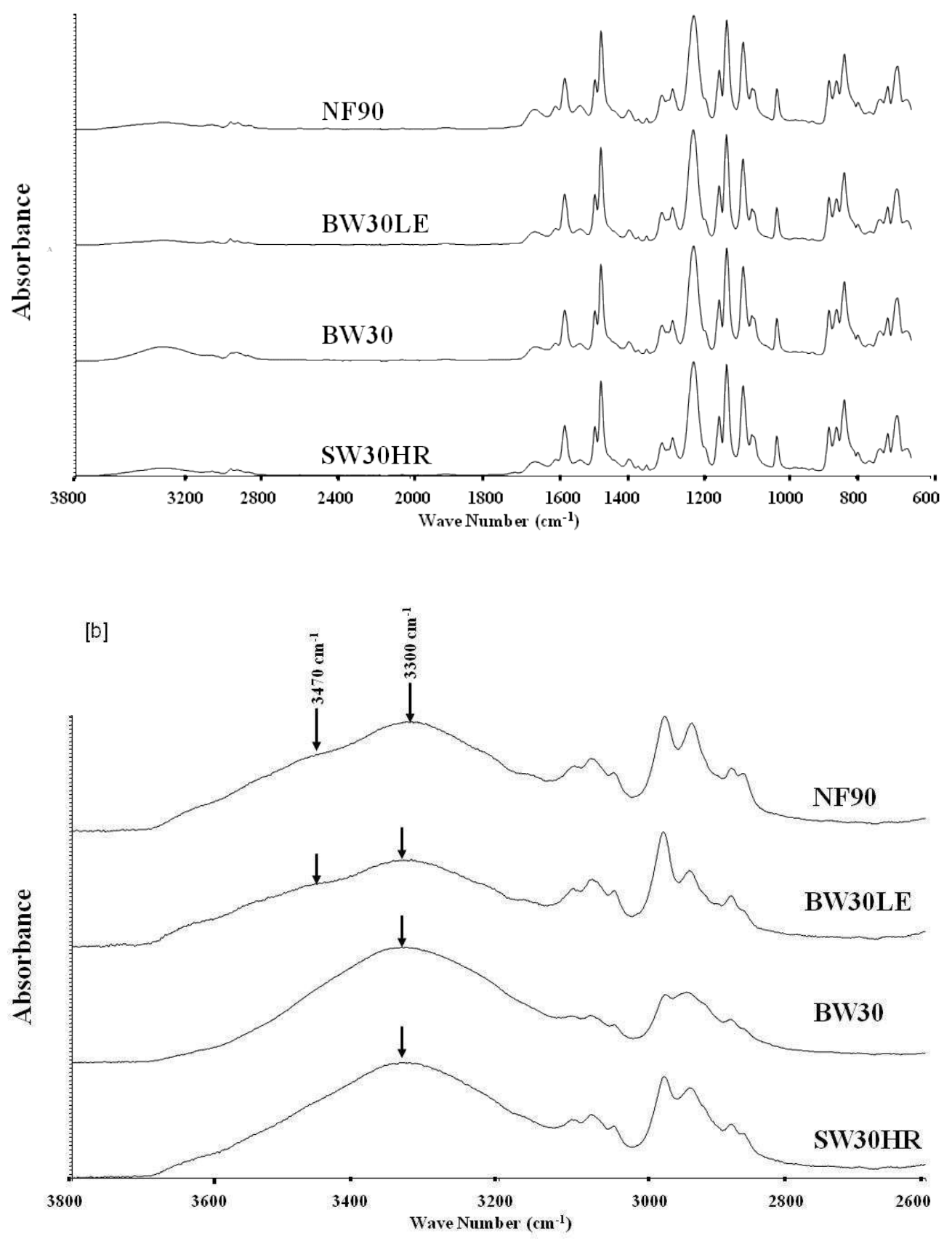

Fig. 3: [a] ATR-FTIR spectra of NF90, BW30LE, BW30 and SW30HR membranes. Bands assignable to polyamide: 1541,1609 and $1641 \mathrm{~cm}^{-1}$; Bands assignable to polysulfone: 1145 , 1180, 1235, 1280, 1350, 1385, 1488 and $1587 \mathrm{~cm}^{-1}$; [b] Enlargement of ATR-FTIR spectra in the range 2600-3800 $\mathrm{cm}^{-1}$. The arrows at $3470 \mathrm{~cm}^{-1}$ (NF90 and BW30LE membranes) indicate $\mathrm{N}-\mathrm{H}$ stretching band of amide groups overlapped with $\mathrm{O}-\mathrm{H}$ stretching band (see arrows at $3300 \mathrm{~cm}^{-1}$ ). 
Fig. 4 shows the zeta potential (determined from Eq. (2)) of NF90, BW30LE, BW30 and SW30HR membranes as a function of $\mathrm{pH}$. The isoelectric point (i.e.p.) of NF90 and BW30LE membranes is around 4 and 4.5, respectively. For $\mathrm{pH}>$ i.e.p., the zeta potential of both membranes is negative due to deprotonation of the $-\mathrm{COOH}$ groups of the polyamide skin layer. The zeta potential first increases (in absolute value) sharply with $\mathrm{pH}$ before leveling-off as dissociation of carboxylic acid groups tend to be complete. Interestingly, the electrokinetic features of both BW30 and SW30HR membranes are different from those of NF90 and BW30LE membranes as shown in Fig. 4. Indeed, the leveling-off of the zeta potential observed for BW30 and SW30HRunder the pH higher than 6 is followed by a rather sharp increase (in absolute value) for $\mathrm{pH}>\sim 9$. That is the signature of ionization of functional groups with very weak acid properties such as alcohols (for example, the $p K_{a}$ of PVA is reported to be about 10.6 [24]) and so results shown in Fig. 4 corroborate the conclusion drawn from the ATR-FTIR study (Fig. 3b).

It can be noticed that BW30 and BW30LE membranes exhibit identical i.e.p. (4.5), which indicates that the fully aromatic polyamide skin layer of BW30 is not completely covered by the coating layer. Moreover, the presence of a very weak acid coating material such as PVA also justifies the less negative zeta potential of the BW30 membrane with respect to that of the BW30LE membrane since the coating layer is neutral except at very high $\mathrm{pH}$.

To the best of our knowledge it is the first time that the presence of coating layers onto RO membranes is put in evidence by means of electrokinetic measurements. It is recommended to conduct these experiments under controlled atmosphere (using an inert gas such as nitrogen) since the dissolution of carbon dioxide in the air is likely to hide the characteristic electrokinetic response of the ionization of very weak acid functions. Indeed, because $\mathrm{pH}$ cannot be kept constant in the basic range in the presence of carbon dioxide, it has to be readjusted frequently during experiments performed at ambient air. That leads progressively to an increase in the electric conductivity of the electrolyte solution (compared with experiments performed under nitrogen environment), which in turn impacts the electrokinetic measurements (typically, the zeta potential decreases as the ionic concentration of the background solution increases). This is illustrated in Fig. 4 that shows a comparison of the zeta potential of the BW30 membrane obtained with and without controlled atmosphere (the ionization of the coating layer is much more obvious for electrokinetic measurements performed with a degassed background solution). Similar results were obtained with the SW30HR membrane (results not shown). 


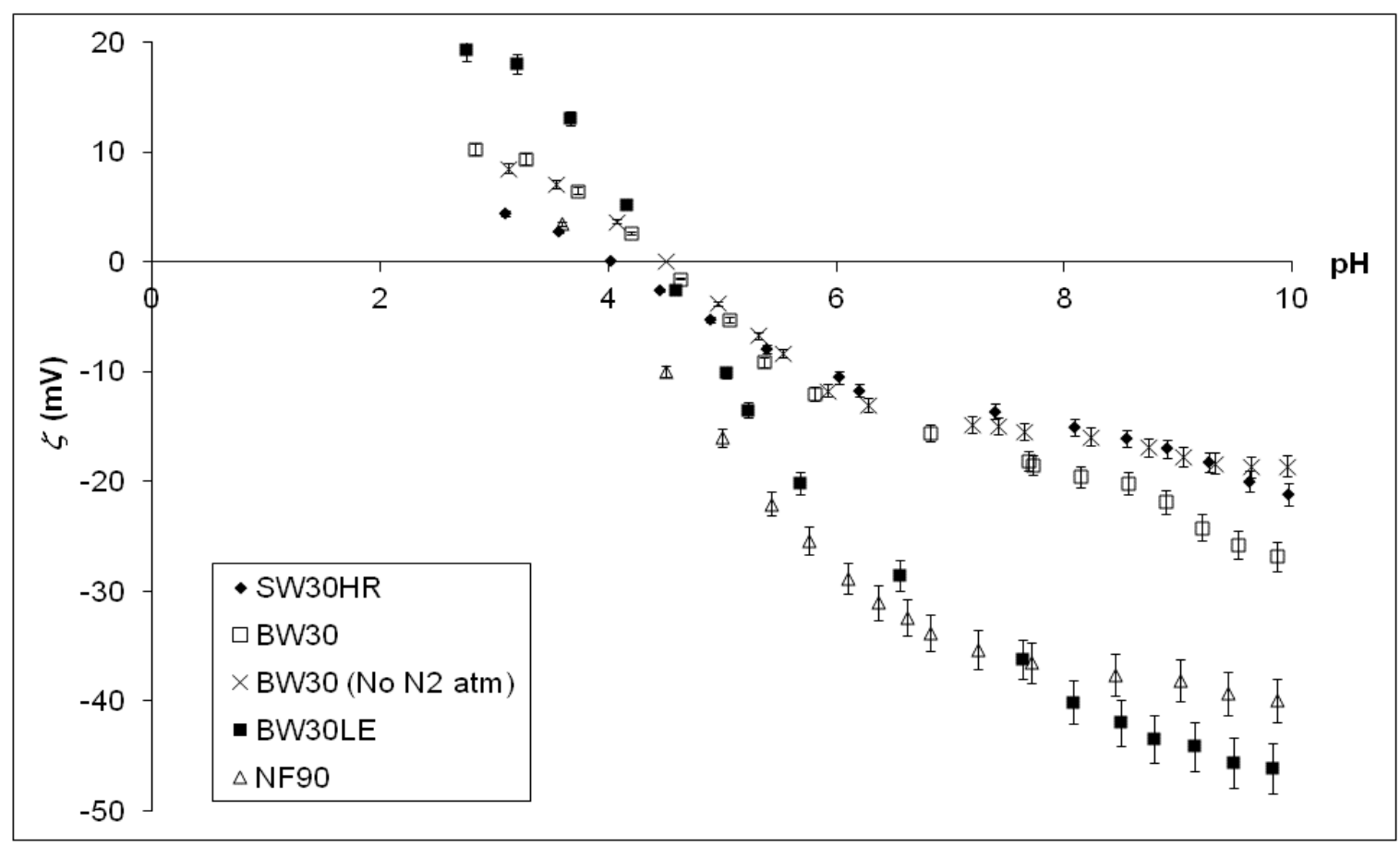

Fig. 4: $\mathrm{pH}$ dependence of zeta potential of NF90, BW30LE, BW30 and SW30HR membranes; For the BW30 membrane, measurements were also performed without controlled atmosphere (cross symbols). Error bars correspond to two successive measurements.

Fig. 5 shows the $\mathrm{pH}$ dependence of the zeta potential of NF270, TFC-SR2 and TFC-SR3 NF membranes, which have semi-aromatic polyamide skin layers. According to the above discussion, it can be concluded that the TFC-SR2 membrane is coated by a layer containing very weak acid functions (such as alcohols) whereas NF270 and TFC-SR3 membranes are not coated. Unlike what was observed for BW30 and BW30LE membranes, TFC-SR2 and TFCSR3 membranes exhibit different i.e.p. (4.8 and 4.2, respectively) but rather similar zeta potentials. It suggests that the synthesis process of the polyamide skin layer is different for TFC-SR2 and TFC-SR3 membranes whereas BW30 and BW30LE seem to differ merely by the post-treatment of the BW30 membrane. 


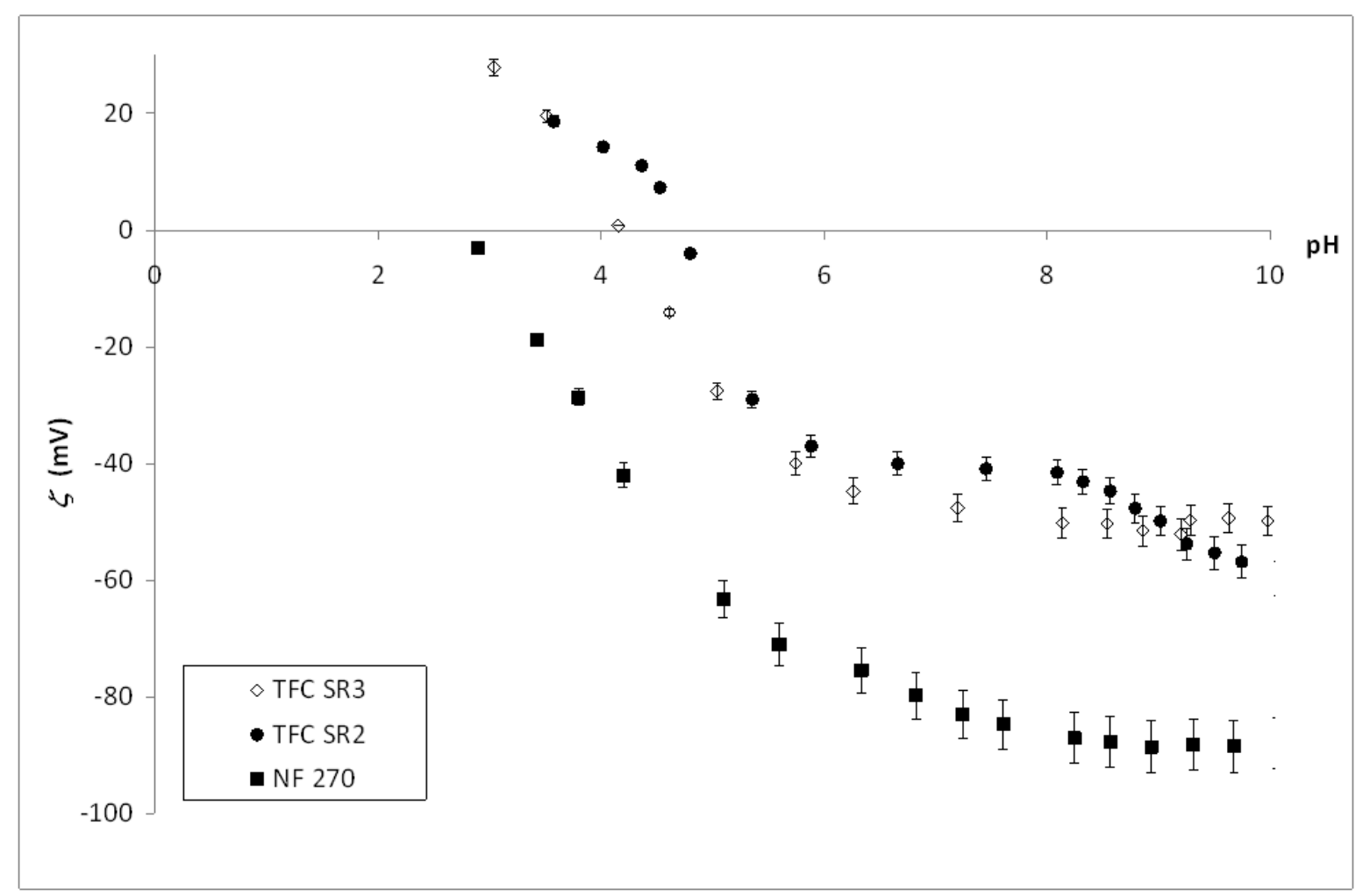

Fig. 5: pH dependent zeta potential curves of NF270, TFC-SR2 and TFC-SR3 membranes. Error bars correspond to two successive measurements.

Table 1 shows a collection of the i.e.p. reported in literature for the different membranes characterized in the present work. Substantial discrepancies appear among the different published results and with results obtained in the present work as well. That can be partly attributed to the variability between different membrane samples but also to the different experimental protocols (electrokinetic technique [13-16], experimental conditions [18] or type of measuring cell [25]). It is worth noting that all data collected in Table 1 were obtained from tangential streaming potential measurements performed at a single channel height, and are therefore likely to provide less accurate zeta potential than streaming current measurements [15-17]. 


\begin{tabular}{|c|c|c|c|}
\hline Membrane & i.e.p. & Background electrolyte & Reference \\
\hline \multirow[t]{4}{*}{ BW30 } & 3.5 & $1 \mathrm{mM} \mathrm{KCl}$ & [26] \\
\hline & 5 & Not indicated & {$[6]$} \\
\hline & 4.2 & $20 \mathrm{mM} \mathrm{NaCl}+1 \mathrm{mM} \mathrm{NaHCO}_{3}$ & [27] \\
\hline & 4 & $10 \mathrm{mM} \mathrm{KCl}$ & {$[28,29]$} \\
\hline \multirow[t]{2}{*}{ BW30LE } & 4 & $10 \mathrm{mM} \mathrm{NaCl}$ & [30] \\
\hline & 3.3 & $1 \mathrm{mM} \mathrm{NaCl}$ & [31] \\
\hline \multirow[t]{2}{*}{ SW30HR } & No i.e.p. & $0.1 \mathrm{mM} \mathrm{KCl}$ & {$[32]$} \\
\hline & 2.7 & $1 \mathrm{mM} \mathrm{KCl}$ & {$[33]$} \\
\hline \multirow[t]{3}{*}{ NF90 } & 5 & $10 \mathrm{mM} \mathrm{NaCl}$ & {$[34]$} \\
\hline & 4.3 & $20 \mathrm{mM} \mathrm{NaCl}+1 \mathrm{mM} \mathrm{NaHCO} 3$ & {$[27]$} \\
\hline & 4 & $10 \mathrm{mM} \mathrm{KCl}$ & {$[28,29]$} \\
\hline \multirow[t]{4}{*}{ NF270 } & 3.5 & $10 \mathrm{mM} \mathrm{NaCl}$ & {$[34]$} \\
\hline & No i.e.p. & $10 \mathrm{mM} \mathrm{KCl}$ & {$[28]$} \\
\hline & 4.8 & $10 \mathrm{mM} \mathrm{KCl}$ & [29] \\
\hline & 4 & $1 \mathrm{mM} \mathrm{KCl}$ & {$[35]$} \\
\hline \multirow[t]{4}{*}{ TFC-SR2 } & 3 & $20 \mathrm{mM} \mathrm{NaCl}+1 \mathrm{mM} \mathrm{NaHCO} 3$ & [36] \\
\hline & 2.5 & $10 \mathrm{mM} \mathrm{KCl}$ & {$[28]$} \\
\hline & 4.25 & $20 \mathrm{mM} \mathrm{NaCl}+1 \mathrm{mM} \mathrm{NaHCO} 3$ & {$[37]$} \\
\hline & $<3$ & $1 \mathrm{mM} \mathrm{KCl}$ & {$[38]$} \\
\hline \multirow[t]{2}{*}{ TFC-SR3 } & 3.84 & $20 \mathrm{mM} \mathrm{NaCl}+1 \mathrm{mM} \mathrm{NaHCO} 3$ & {$[37]$} \\
\hline & $<3$ & $1 \mathrm{mM} \mathrm{KCl}$ & {$[38]$} \\
\hline ESPA4 & 4.1 & $20 \mathrm{mM} \mathrm{NaCl}+1 \mathrm{mM} \mathrm{NaHCO} 3$ & {$[27]$} \\
\hline
\end{tabular}

Table 1: Isoelectric points (i.e.p.) of various NF and RO membranes reported in the literature.

As shown above, the streaming current technique allows a clearer discrimination between coated and uncoated NF/RO membranes than the ATR-FTIR technique because electrokinetic 
measurements are sensitive to ionization of the coating layer at high $\mathrm{pH}$. The interest of the streaming current technique is emphasized by the results shown in Figs. 6 and 7 which were obtained with ESPA4 and i-phobe 2 membranes. Fig. 6 shows the ATR-FTIR spectra of both membranes in the range of $2600-3800 \mathrm{~cm}^{-1}$. A shoulder peak at $3470 \mathrm{~cm}^{-1}$ is observed near the wide band centered at $3300 \mathrm{~cm}^{-1}$, which corresponds to the overlap of the stretching vibration bands of N-H and carboxylic groups of the polyamide layer (as observed for both NF90 and BW30LE membranes in Fig.3b). ATR-FTIR results therefore suggest that none of these membranes contains alcohol functions. Although this conclusion is supported by streaming current experiments for the ESPA4 membrane, electrokinetic measurements reported in Fig. 7 clearly put in evidence the presence of alcohol functions on the surface of the i-phobe 2 membranes (see the sharp increase in the zeta potential for $\mathrm{pH}>\sim 9$ resulting from the dissociation of hexafluoroalcohol functions having a $p K_{a}$ around 10 [39]).

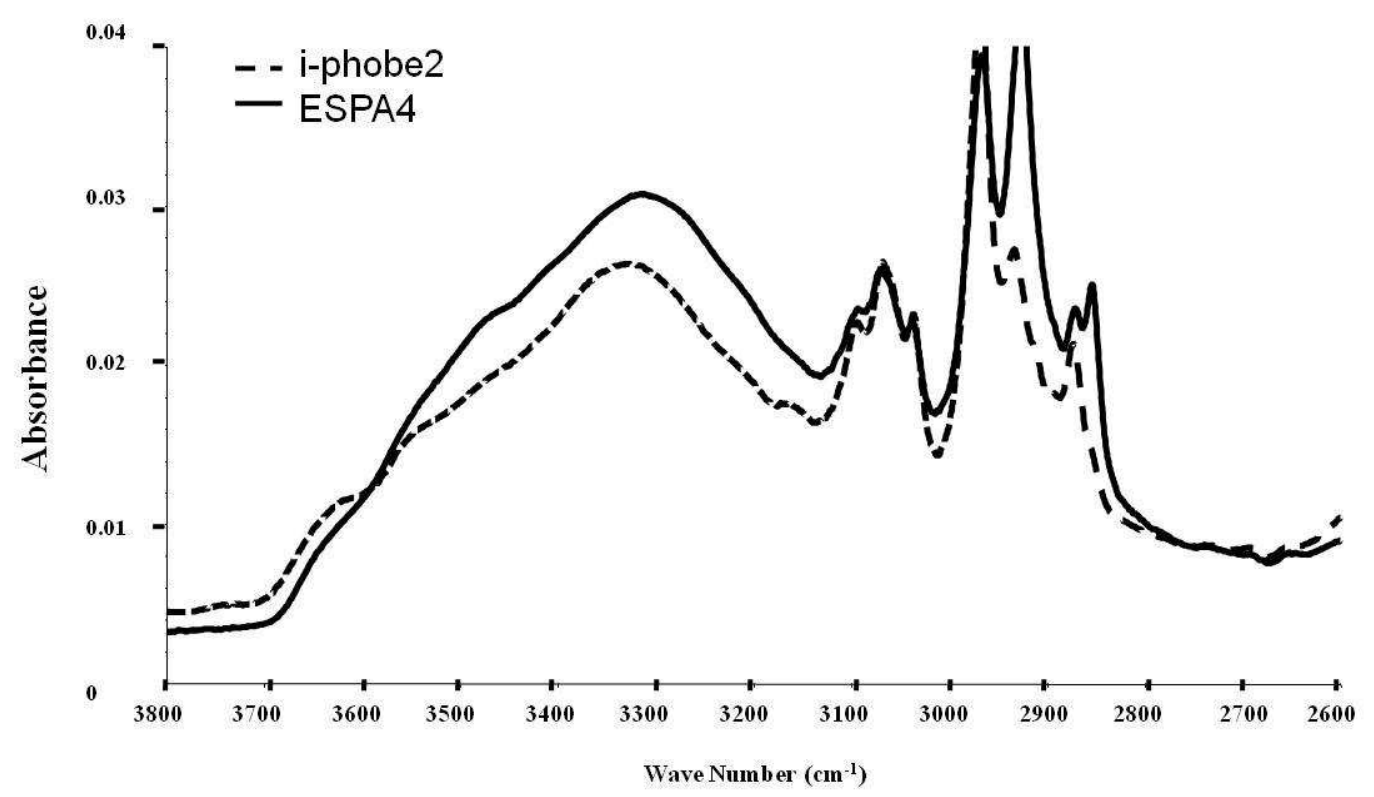

Fig. 6: ATR-FTIR spectra of ESPA4 and i-phobe 2 membranes in the range $2600-3800 \mathrm{~cm}^{-1}$.

Fig. 7 also shows the comparison between zeta potentials of the i-phobe 2 membrane inferred from streaming current measurements performed with and without controlled atmosphere. In passing, it can be noticed that most electrokinetic studies on membranes reported in the literature were carried out under ambient-air conditions [12, 15, 16, 18, 20, 25-33, 35-38]). To our knowledge only one work reports explicitly that electrokinetic measurements (streaming 
potential) were performed with degassed background electrolyte solution [40]. It is also worth mentioning that with some electrokinetic devices the background electrolyte solution is circulated by means of pressurized nitrogen gas $[11,14,17]$. However, such systems do not allow removing efficiently carbon dioxide from the measuring solution since this latter must be reset to atmospheric pressure periodically (whenever the solution flow is reversed during measurements) $[11,14,17]$. As shown in Fig. 7 , zeta potential values are independent of the experimental protocol for $\mathrm{pH}$ lower than $\sim 5$, i.e. in the $\mathrm{pH}$ range for which the amount of both bicarbonate and carbonate ions is negligible $\left(p K_{a}\left(\mathrm{H}_{2} \mathrm{CO}_{3} / \mathrm{HCO}_{3}{ }^{-}\right)=6.35\right.$ and $p K_{a}\left(\mathrm{HCO}_{3}{ }^{-}\right.$ $\left./ \mathrm{CO}_{3}{ }^{2-}\right)=10.33$ ). On the other hand, substantial differences between zeta potentials appear for higher $\mathrm{pH}$, which can be attributed to the presence of $\mathrm{HCO}_{3}{ }^{-}$and $\mathrm{CO}_{3}{ }^{2-}$ ions resulting from the dissolution of carbon dioxide from the ambient air in the electrolyte solution. As mentioned previously, in the basic range the electric conductivity of the background solution is higher under ambient air conditions than under controlled atmosphere (see Fig. 8), which is expected to decrease the zeta potential (in absolute value) as observed in Fig. 4 for the BW30 membrane. However, Fig. 7 shows that the zeta potential of the i-phobe 2 membrane is found to be more negative under ambient air conditions despite this "conductivity effect". This finding suggests that $\mathrm{HCO}_{3}{ }^{-}$and $\mathrm{CO}_{3}{ }^{2-}$ anions adsorb substantially onto the surface of the iphobe 2 membrane such that the increase in the negative charge density resulting from anion adsorption overcompensates the effect of conductivity. It can be noted that for $\mathrm{pH}$ higher than 10, the increase in the conductivity measured at ambient air is so high (see Fig. 8) that the effect of conductivity becomes more important than that of anion adsorption and so the zeta potential decreases (in absolute value) as shown in Fig. 7. It is worth mentioning that specific adsorption of bicarbonate and carbonate ions has also been observed on the surface of metal oxide nanoparticles in the earlier literature [41].

Finally, since conductivity and adsorption of anions coming from the dissolution of carbon dioxide have opposite effects on the zeta potential, it should be stressed that results shown in Fig. 4 do not allow to conclude about the possible adsorption of bicarbonate and/or carbonate ions onto the BW30 membrane (for instance, adsorption might occur but the impact on the zeta potential might be "hidden" by a dominant conductivity effect). 


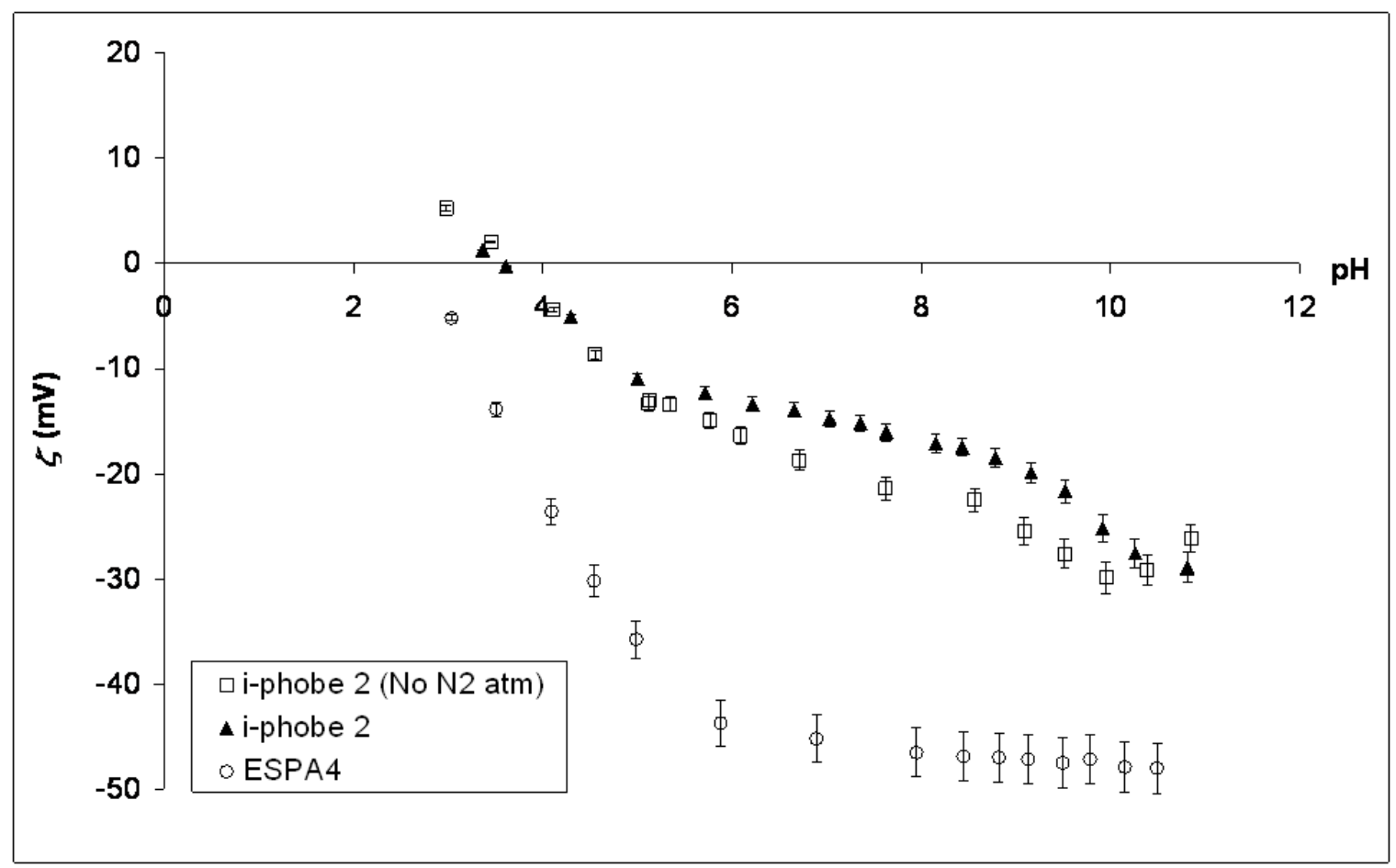

Fig. 7: $\mathrm{pH}$ dependent zeta potential curves of ESPA4 and i-phobe 2 measured under $\mathrm{N}_{2}$ atmosphere. For i-phobe 2 membrane, measurements were also performed without controlled atmosphere (square symbols). Error bars correspond to two successive measurements.

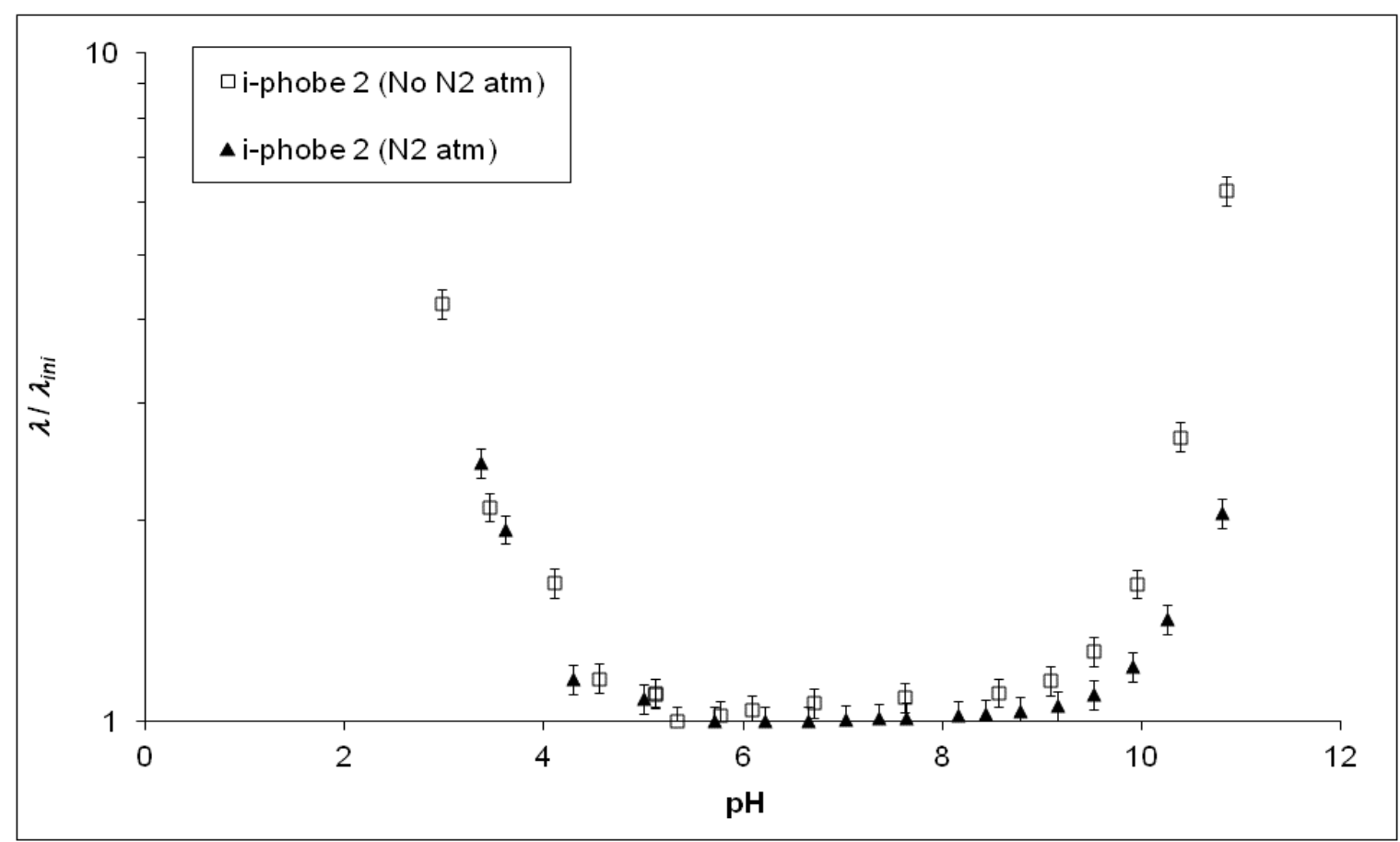

Fig. 8: Variation of the electric conductivity $\lambda$ of the electrolyte solution (scaled to the electric conductivity of the initial $\mathrm{KCl}$ solution $\left(\lambda_{\text {ini }}\right)$, i.e. before any $\mathrm{pH}$ adjustment) as a function of $\mathrm{pH}$ for experiments performed with and without controlled atmosphere. Error bars correspond to two successive measurements. 


\section{Conclusion}

Characterization of the electrical surface properties of NF/RO membranes through the determination of their zeta potential is essential to understand the separation performance of these materials. In this work, we performed streaming current measurements in tangential mode with a variety of NF and RO membranes by applying an experimental protocol requiring degassed background solutions and a nitrogen inert environment. It was shown for the first time that the streaming current technique enables to highlight the presence of coating layers onto NF/RO membranes. It was also shown that the streaming current technique allows a more clear discrimination between coated and uncoated NF/RO membranes than the ATRFTIR technique because streaming current measurements are sensitive to the ionization of the functional groups carried by the coating layer. Performing electrokinetic measurements under a controlled atmosphere such as a nitrogen environment was shown to be important for $\mathrm{pH}>$ $\sim 5$ since the $\mathrm{pH}$ drop resulting from the dissolution of carbon dioxide in the air requires to readjust the $\mathrm{pH}$ frequently, resulting in an increase in the electric conductivity of the background solution which in turn impacts the electrokinetic measurements. Moreover, experiments performed with and without the presence of carbon dioxide revealed specific adsorption of bicarbonate and carbonate ions onto the surface of RO polyamide membranes containing hexafluoroalcohol functional groups.

\section{Acknowledgements}

This work has been partly funded by the Agence Nationale de la Recherche through the research program MUTINA (ANR 2011 BS09 002).

The authors are grateful to Koch Membrane Systems for TFC-SR2 and TFC-SR3 membrane samples, Hydranautics for ESPA4 samples and IBM for i-phobe 2 samples. 


\section{References}

[1] A.C. Sagle, E.M. Van Wagner, H. Ju, B.D. Mcloskey, PEG-coated reverse osmosis membranes: Desalination properties and fouling resistance, J. Membr. Sci. 340 (2009) 92108.

[2] Q. Li, X. Pan, Z. Qu, X. Zhao, Y. Jin, H. Dai, B. Yang, X. Wang, Understanding the dependence of contact angles of commercially RO membranes on external conditions and surface features, Desalination 309 (2013) 38-45.

[3] M. Elimelech, W.A. Phillip, The Future of Seawater Desalination: Energy, Technology, and the Environment, Science. 333 (2011)712-717.

[4] A. Widjaya, T. Hoang, G.W. Stevens, S.E. Kentish, A comparison of commercial reverse osmosis membrane characteristics and performance under alginate fouling conditions, Sep. Purif. Technol, 89 (2012) 270-281.

[5] T. Mezher, H. Fath, Z. Abbas, A. Khaled, Techno-economic assessment and environmental impacts of desalination technologies, Desalination 266 (2011) 263-273.

[6] C.Y. Tang, Y-N Kwon, J.O. Leckie, Probing the nano-and micro-scales of reverse osmosis membranes- A comprehensive characterization of physiochemical properties of uncoated and coated membranes by XPS, TEM, ATR-FTIR, and streaming potential measurements, J. Membr. Sci. 287 (2007) 146-156.

[7] C.Y. Tang, Y-N. Kwon, J.O. Leckie, Effect of membrane chemistry and coating layer on physiochemical properties of thin film composite polyamide RO and NF membranes II. Membrane physiochemical properties and their dependence on polyamide and coating layers, Desalination 242 (2009) 168-182.

[8] E. Dražević, K. Košutić, V. Dananić, D. Mutavdžić Pavlović, Coating layer effect on performance of thin film nanofiltration membrane in removal of organic solutes, Sep. Purif. Technol. 118 (2013) 530-539.

[9] Q. Li, X. Pan, C. Hou, Y. Jin, H. Dai, H. Wang, X. Zhao, X. Liu, Exploring the dependence of bulk properties on surface chemistries and microstructures of commercially composite RO membranes by novel characterization approaches, Desalination 292 (2012) 918.

[10] K. Kimura, G. Amy, J.E. Drewes, T. Heberer, T.U. Kim, Y. Watanabe, Rejection of organic micropollutants (disinfection by-products, endocrine disrupting compounds, and pharmaceutically active compounds) by NF/RO membranes, J. Membr. Sci. 227 (2003) 113. 
[11] A.I. Cavaco Morão, A. Szymczyk, P. Fievet, A. M. Brites Alves, Modelling the separation by nanofiltration of a multi-ionic solution relevant to an industrial processJ. Membr. Sci,322 (2008) 320-330.

[12] A.E. Childress, M. Elimelech, Relating nanofiltration membrane performance to membrane charge (electrokinetic) characteristics, Environ. Sci. Technol. 34 (2000) 3710.

[13] A.E Yaroshchuk, V. Ribitsch, Role of channel wall conductance in the determination of z-potential from electrokinetic measurements, Langmuir 18 (2002) 2036-2038.

[14] P. Fievet, M. Sbaï, A. Szymczyk, A. Vidonne, Determining the z-potential of plane membranes from tangential streaming potential measurements: effect of the membrane body conductance,J. Membr. Sci, 226 (2003) 227-236.

[15] A. Yaroshchuk, T. Luxbacher, Interpretation of Electrokinectic Measurements with porous Films: Role of Electric Conductance and Streaming Current within porous Structure, Langmuir 2010, 26(13), 10882-10889.

[16] A. Szymczyk, Y. Ibrahim Dirir, M. Picot, I. Nicolas, F. Barrière, Advanced electrokinetic characterization of composite porous membranes, J. Membr. Sci 429 (2013) 44-51.

[17] S. Déon, P. Fievet, C. Osman Doubad, Tangential streaming potential/current measurements for the characterization of composite membranes, J. Membr. Sci 423-424 (2012) 413-421.

[18] A. Yaroshchuk, E.E. Licón Bernal, T. Luxbacher, Electrokinetics in undeveloped flows, J. Colloid Interface Sci. 410 (2013) 195-201.

[19] R.J. Hunter, Introduction to modern colloid science, Oxford University Press Inc, NewYork, 1996.

[20] C. Werner, H. Körber, R. Zimmermann, S. Dukhin, H.J. Jacobasch, Extented electrokinetic characterization of flat solid surfaces, J. Colloid Interface Sci. 208 (1998) 329346.

[21] R. Zimmermann, N. Rein, C. Werner, Water ion adsorption dominates charging at nonpolar polymer surfaces in multivalent electrolytes, Phys. Chem. Chem. Phys. 11 (2009) 4360-4364.

[22] Y-H. La, J. Diep, R. Al-Rasheed, D. Miller, L. Krupp, G.M. Geise, A. Vora, B. Davis, M. Nassar, B.D. Freeman, M. McNeil, G. Dubois, Enhanced desalination performance of polyamide bi-layer membranes prepared by sequential interfacial polymerization, J. Membr. Sci 437 (2013) 33-39.

[23] http://www.anton-paar.com/US/en/60/161\#Downloads.Manuals. 
[24] W.M. Hosny, P.A. Khalaf-Alaa, Potentiometric Study and Biological Activity of Some Metal Ion Complexes of Polyvinyl Alcohol (PVA), Int. J. Electrochem. Sci., 8 (2013) 15201533.

[25] H. Buksek, T. Luxbacher, I. Petrinic, Zeta potential determination of polymeric materials using two differently designed measuring cells of an electrokinetic analyzer, Acta Chim. Slov. 57 (2010) 700-706.

[26] C. Fargues, C. Sagne, A. Szymczyk, P. Fievet, M.L. Lamelloise, Adsorption of small organic solutes from beet distillery condensates on reverse-osmosis membranes: consequences on the process performances, J. Membr. Sci. 446 (2013) 132-144.

[27] L.A. Richards, M. Vuachère, A.I. Schäfer, Impact of $\mathrm{pH}$ on the removal of fluoride, nitrate and boron by nanofiltration/reverse osmosis, Desalination 261 (2010) 331-337.

[28] A. Simon, L.D. Nghiem, P. Le-Clec, S.J. Khan, J.E. Drewes, Effects of membrane degradation on the removal of pharmaceutically active compounds ( $\mathrm{PhACs}$ ) by NF/RO filtration processes, J. Membr. Sci. 340 (2009) 16-25.

[29]K.L. Tu, L.D. Nghiem, A.R. Chivas, Coupling effects of feed solution $\mathrm{pH}$ and ionic strength on the rejection of boron by NF/RO membranes, Chem. Eng. J. 168 (2011) 700-706.

[30] K. Kezia, J. Lee, A.J. Hill, S.E. Kentish, Convective transport of boron through a brackish water reverse osmosis membrane, J. Membr. Sci. 445(2013)160-169.

[31] J. Lee, A.J. Hill, S.E. Kentish, Formation of a thick aromatic polyamide membrane by interfacial polymerisation, Sep. Purif. Technol. 104 (2013) 276-283.

[32] W. Lee, C.H. Ahn, S. Hong, S. Kim, S. Lee, Y. Baek, J. Yoon, Evaluation of surface properties of reverse osmosis membranes on the initial biofouling stages under no filtration condition, J. Membr. Sci. 351 (2010) 112-122.

[33] E. Ould Mohamedou, D.B. Penate Suarez, F. Vince, P. Jaouen, M. Pontié, New lives for old reverse osmosis (RO) membranes, Desalination 253 (2010) 62-70.

[34] C.Y. Tang, Y.N. Kwon, J.O. Leckie, Characterization of humic acid fouled reverse osmosis and nanofiltration membranes by transmission electron microscopy and streaming potential measurements, Environ. Sci. Technol. 41 (2007) 942-949.

[35] Y.L. Lin, P.C. Chiang, E.E. Chang, Removal of small trihalomethane precursors from aqueous solution by nanofiltration, J. Hazard. Mater. 146 (2007) 20-29.

[36] L.D. Nghiem, A.I. Schäfer, M. Elimelech, Role of electrostatic interactions in the retention of pharmaceutically active contaminants by a loose nanofiltration membrane, J. Membr. Sci. 286 (2006) 52-59. 
[37] A. De Munari, A.J. Correia Semiao, B. Antizar-Ladislao, Retention of pesticide Endosulfan by nanofiltration: Influence of organic matter-pesticide complexation and solutemembrane interactions, Water Research 47 (2013) 3484-3496.

[38] M.A. Zazouli, H. Susanto, S. Nasseri, M. Ulbricht, Influences of solution chemistry and polymeric natural organic matter on the removal of aquatic pharmaceutical residuals by nanofiltration, Water Research 43 (2009) 3270-3280.

[39] Y-H. La, R. Sooriyakumaran, D. C.Miller, M. Fujiwara, Y. Terui, K. Yamanaka, B.D. McCloskey, B.D. Freeman and R.D. Allen, Novel thin film composite membrane containing ionizable hydrophobes: $\mathrm{pH}$-dependent reverse osmosis behavior and improved chlorine resistance, J. Mater. Chem, 2010, 20, 4615-4620.

[40] C.Y. Tang, Q. Shian Fu, A.P. Robertson, C.S. Criddle, J.O. Leckie, Use of reverse osmosis membranes to remove perfluorooctane sulfonate (PFOS) from semiconductor wastewater, Environ. Sci. Technol. 40 (2006) 7343-7349.

[41] N. Wang, C. Hsu, L. Zhu, S. Tseng, J.P. Hsu, Influence of metal oxide nanoparticles concentration on their zeta potential, J. Colloid Interface Sci. 407 (2013) 22-28. 